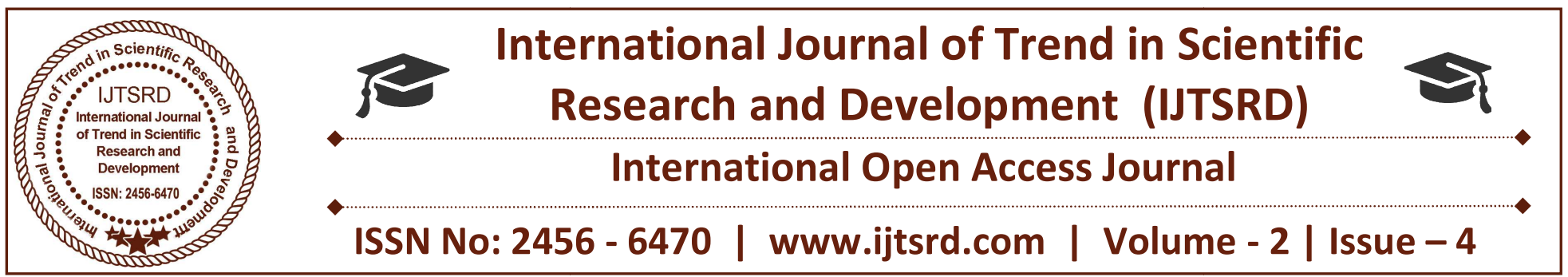

\title{
Mitigation of Voltage dip in WECS using UPQC
}

\author{
Sajid Bashir ${ }^{1}$, Gagan Deep Yadav ${ }^{2}$ \\ ${ }^{1}$ M.Tech Scholar, ${ }^{2}$ Assistant Professor \\ Electrical Engineering Department, \\ Yamuna Institute of Engineering \& Technology, Gadhauli, Yamunanagar, Haryana, India
}

\begin{abstract}
Currently, the quality of supplied power is important to several customers. Power quality is a service and many customers are ready to pay for it. In the future, distribution system operators could decide, or could be obliged by authorities, to supply their customers with different PQ levels and at different prices. A new device that can fulfill this role is the unified power quality conditioner (UPQC), composed of a powerelectronic series main unit installed in the mediumvoltage/low-voltage (LV) substation, along / with several power-electronic shunt units connected close to the end users. The series and parallel units do not have a common dc link, so their control strategies are different than traditional UPQC control techniques. This device can achieve general improvement in power quality, reducing the most common disturbances for all customers that are supplied by the mains by using only the series unit. Additional increments in power quality (i.e., mains power interruptions, faults), can be provided to the customers who need it (custom power) by the shunt units. The UPQC is controlled to mitigate voltage fluctuations and to regulate the WF terminal voltage at PCC caused by pulsating WF generated power and system load changes respectively. Simulation results show that there is reduction in power fluctuations at grid and voltage fluctuations at PCC. The UPQC scheme is validated to mitigate the power quality problems like Voltage Sag, Swell and Harmonics and WF stability.
\end{abstract}

Keywords: Ancillary services, Frequency response, Emulating inertia, Primary frequency control, Wind turbines

\section{INTRODUCTION}

Power quality is very important to certain customers. For this reason, many utilities could sell electrical energy at different prices to their customers, depending on the quality of the delivered electric power. Since most end users are connected to secondary distribution networks, at low voltage (LV), it could be important to monitor and compensate the main disturbances on the LV grid. Specifically, it has been reported in a survey [1] that, in the Southeastern region of the U.S., most monitored industrial customers and main end users did not suffer long outages. Rather, they experienced numerous short duration voltage sags and momentary interruptions. Therefore, local utility companies had to re configure their systems to keep their most important customer on-line.

Various solutions are available to compensate for these disturbances. One solution involves increasing the short circuit level of the distribution network, i.e., revamping all the LV distribution cables or raising the power of the MV/LV substation transformer, thus increasing the power quality for all end users. In this way, an incoming disturbance from a load (i.e., harmonics) or from a fault in a line is reduced at the point of common coupling (PCC). Therefore, this solution effectively reduces the depth of the voltage variations, but does not protect the loads against transients and short interruptions. A second solution that can compensate any kind of disturbance, including interruptions, is installation [2] of on-line, off-line, line interactive and hybrid UPS systems. In all of these cases, only the end users that decide to install them are protected, while all of the other costumers do not receive any improvement in power 
quality. Often, these solutions cannot be adopted by the local utility companies or by the end users, because they are too expensive relative to the increase in power quality that they produce. However, many cheaper solutions are available. In particular, several electronic devices have been developed, studied and proposed to the international scientific community with the goal of improving supplied power quality. In [3]-[10], various single apparatus are analyzed. Different connection topologies (series or shunt types) are used to realize these devices. The series devices are connected upstream of the protected lines, while the shunt devices are connected in parallel to the sensitive loads. In general, both types of conditioning devices increase the power quality level at the loads, as reported in [3]-[7] for series devices and in [8][10] for shunt devices.

Other studies have been carried out to consider combinations of the previous single apparatus solutions (as UPS, UPLC, UPQC, etc.). The unified power quality conditioner (UPQC) compensator seems to be a particularly promising power conditioner device. This apparatus is constituted of a series and a shunt unit, with a common de section through which power can be exchanged. Its function is to improve the quality levels of the current absorbed at the mains and the load supply voltage [2], [11]. However, these devices do not allow local distributors to guarantee different quality demand levels to the final customers, because they improve power quality for all the supplied end users. The installation investments are also quite high relative to the power quality level obtained. A solution that has similar performances and advantages, but also makes cost reduction possible, is the proposed UPQC.

This new solution, analyzed in [12], [13], starts from the UPQC configuration, removes the common dc connection and splits the shunt unit into several shunted devices. Therefore, the control strategy is different than the traditional combined series and shunt converters, but the improvements to load voltage and network current quality are quite similar. Above all, the UPQC can stabilize load voltage, increase the network power factor, leading to keep load voltage and network current sinusoidal and balanced as well. The series main unit is installed in the $\mathrm{MV} / \mathrm{LV}$ substation. In a grid connected configuration, it can stabilize load voltage at the LV busbar (PCC) as the series devices analyzed in [3][7]. The shunt units do not affect the dynamic behavior of the series unit, because their dynamic responses are very slow under these operating conditions. In [6] and [7], the transient behavior of a single dynamic voltage restorer) device was analyzed and simulated, and its working limits were determined. In particular, the device behavior in the presence of voltage sags (i.e. 10\%-20\%) is described.

The several shunt units are connected near the end users that need high power quality. If a storage system is present, they can exchange active power and nonactive power with the electrical system. Especially in a grid-connected configuration, non-active power can be exchanged with the mains in order to enhance the series unit performance and extend its working limits. Otherwise, the users can disconnect themselves when the PCC voltage is out of the operating limits, and the load will be supplied in back-up mode.

\section{THE UNFIED POWER QUALITY CONDITIONER}

Most end user disturbances are characterized by short duration and small amplitude, though they can still cause interruptions in production processes. As the most voltage sags have small depth and short durations [14]. More than $95 \%$ of voltage sags can be compensated by injecting a voltage of up to $60 \%$ of the nominal voltage, with a maximum duration of 30 cycles. This information is primarily used to evaluate a suitable size for the UPQC. The series unit of the UPQC, sized to supply $60 \%$ of the LV network power and equipped with a small storage system, can compensate for most of the voltage disturbances.

Each shunt unit is sized in relation to the supplied load power, and can protect its sensitive load against interruptions. The shunt unit's function is similar to that of the UPS output stage [2], [16], but is less expensive because it only has one conversion stage and involves less power loss.

The UPQC is a power electronics based compensator which works on the principle of active filtering. It is a combination of Shunt (SHUC) and Series (SERC) Compensators, cascaded via a DC link capacitor. As shown in Figure 1. Each compensator of the UPQC consists of an IGBT based full bridge inverter, which may be operated in a voltage or a current controlled mode depending on the control scheme. Inverter I (Series Compensator, SERC) is connected in series with the supply voltage through a linear transformer. Inverter II (Shunt Compensator, SHUC) is connected in parallel to the load through. The SERC operates as a controlled voltage source and compensates for any voltage disturbance in the network. The SHUC 
operates as a controlled current source and compensates for reactive or harmonic elements in the load. It also acts as a real power path and maintains the DC link voltage at a constant value by charging the DC link capacitor continuously.

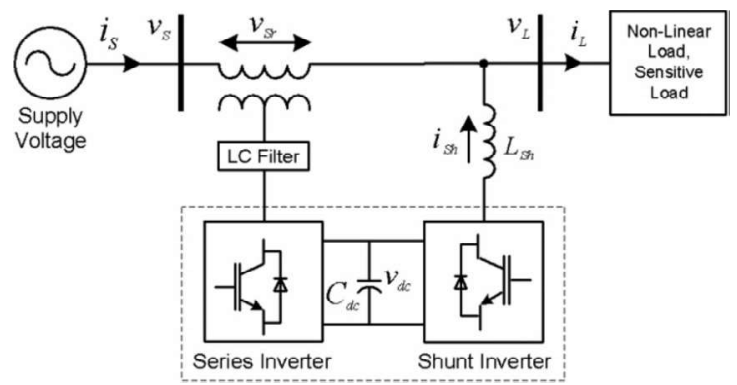

$$
\left[\begin{array}{l}
i_{o} \\
i_{\alpha} \\
i_{\beta}
\end{array}\right]=\sqrt{\frac{2}{3}}\left[\begin{array}{ccc}
\frac{1}{\sqrt{2}} & \frac{1}{\sqrt{2}} & \frac{1}{\sqrt{2}} \\
1 & -\frac{1}{2} & -\frac{1}{2} \\
0 & \frac{\sqrt{3}}{2} & -\frac{\sqrt{3}}{2}
\end{array}\right]\left[\begin{array}{l}
i_{L a} \\
i_{L b} \\
i_{L c}
\end{array}\right]
$$

Equation (3) shows calculation of instantaneous real power $(p)$, imaginary power $(q)$ and zero sequence power $\left(p_{0}\right)$ components drawn by the load

$\left[\begin{array}{c}p_{o} \\ p \\ q\end{array}\right]=\left[\begin{array}{ccc}v_{o} & 0 & 0 \\ 0 & v_{\alpha} & v_{\beta} \\ 0 & -v_{\beta} & v_{\alpha}\end{array}\right]\left[\begin{array}{c}i_{o} \\ i_{\alpha} \\ i_{\beta}\end{array}\right]$

Fig. 1 Basic block diagram of UPQC

$$
\text { Where } p=\bar{p}+\tilde{p} \quad ; q=\bar{q}+\tilde{q}
$$

\section{Control of UPQC}

The UPQC system is inherently complex and requires sophisticated control systems to achieve the satisfactory performance.

The instantaneous reactive power $(p-q)$ theory is used to generate reference signal for shunt APF. The control block diagram of shunt active filter is given in Fig.2. In this theory, the instantaneous three-phase currents and voltages are transformed to $\alpha-\beta-0$ coordinates as shown in equation (1) and (2).

$$
\left[\begin{array}{l}
v_{o} \\
v_{\alpha} \\
v_{\beta}
\end{array}\right]=\sqrt{\frac{2}{3}}\left[\begin{array}{ccc}
\frac{1}{\sqrt{2}} & \frac{1}{\sqrt{2}} & \frac{1}{\sqrt{2}} \\
1 & -\frac{1}{2} & -\frac{1}{2} \\
0 & \frac{\sqrt{3}}{2} & -\frac{\sqrt{3}}{2}
\end{array}\right]\left[\begin{array}{l}
v_{S a} \\
v_{S b} \\
v_{S c}
\end{array}\right]
$$

Where, the ${ }^{\sim}$ sign points to the alternating term and the sign points to the direct component of each active and reactive power. In general, each one of the active and reactive instantaneous power contains a direct component and an alternating component. The direct component of each presents the power of the fundamentals of current and voltage. The alternating term is the power of the harmonics of currents and voltages. 
$\mathrm{V}=$ wind speed.

$\mathrm{T}=$ mechanical torque

$\mathrm{P}=$ output power of the wind turbine.

$\omega_{\mathrm{s}}=$ rotor speed of the wind turbine.

The relation between $C_{p}$ and $\lambda$ is normally established by the $C_{p} / \lambda$ curve. This curve can be approximated using the power/wind curve, provided by the wind turbine manufacturers. To perform this calculation, it is supposed that the rotor speed does not depend on wind speed in steady-state operation. Generic equation is used to model the performance coefficient, $\mathrm{C}_{\mathrm{p}}(\lambda, \beta)$.

The $\mathrm{C}_{\mathrm{p}}-\lambda$ characteristics, for different values of the pitch angle $\beta$, are illustrated in Fig. 2 .

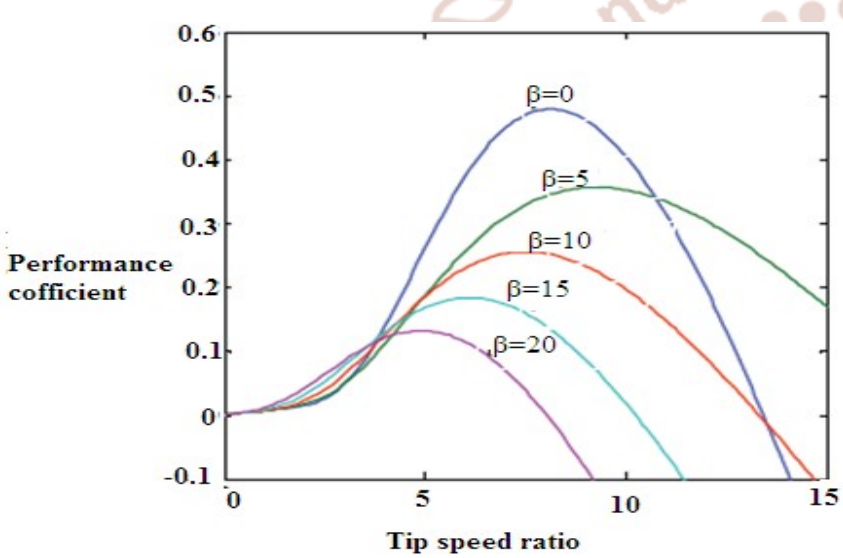

Fig.s reriormance coenincient versus up-speed-ratıo characteristics. order to introduce variable load a three phase breaker is used which can open and close at defined time. The simulation results for supply voltage \& load voltage are presented with UPQC \& without UPQC under three phase fault conditions with different fault durations. Additionally, the simulation result for compensation voltage \& current by UPQC is also presented. From the simulation it is shown that power quality improves with use of UPQC. Model has been built in MATLAB/Simulink software so as to investigate UPQC circuit waveforms. Steady state waveforms of Model have been shown below:

\section{A. Steady state source voltage \& load current without UPQC}

System may become faulty under operating condition and various type of fault may occur like single phase faults, double phase faults and three phase faults. Out of these three phase fault condition is most severe and hence we simulated our system under three different conditions.

The following typical case studies have been simulated and the results are presented.

1) Short duration three phase fault conditions.

2) Long duration three phase fault conditions.

3) Dynamic load and three phase fault conditions.

A three phase fault has been introduced from time 0.3 to $0.4 \mathrm{sec}$. In this model only constant load has been used. Waveforms of Source voltage \& load current has been shown in Fig .4with \& without UPQC.

\section{SIMULATION AND RESULTS}

The simulation models have been developed in MATLAB/SIMULINK environment. The models have been operated for constant \& variable load. In

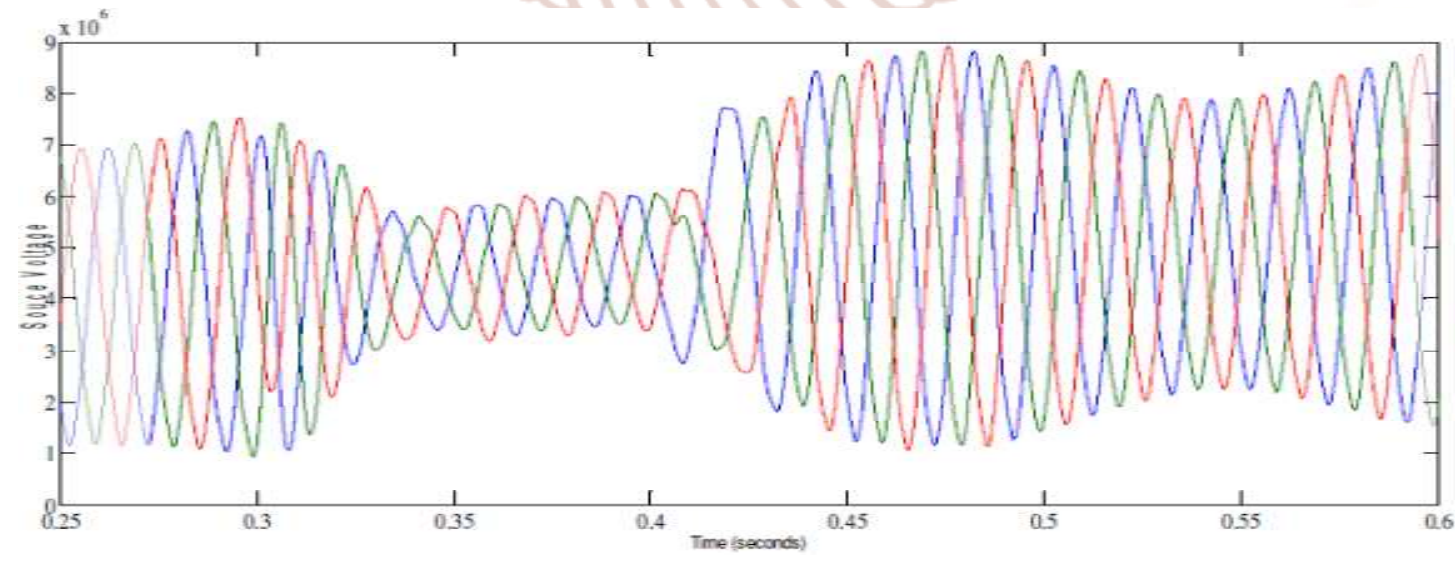

Fig. 4. Source Voltage when a three Phase fault introduced from 0.3 to 0.4 seconds without UPQC 
Source voltage shows a sag or dip from time 0.3 to $0.4 \mathrm{sec}$ as shown in Fig. 4 . As the fault offer virtual shortcircuit in the transmission line that causes voltage dip in the system. In the case of severe fault conditions like L-L-G and L-L-L-G cases this voltage drop has very significant value. This major voltage drop in the transmission network due to fault also increases the current in the system. Due to this problem overall performance of the system reduces.

From the figure 4 it is also found that there is dip in the voltage as well as the phase angle between the three phase voltage is also not 120 degree. This problem can lead to the unbalance current in the system.

\section{B. Source Voltage With UPQC}

In fig. 5. source voltage variation are shown when a three phase fault has been introduced from 0.3 to 0.4 seconds in line with UPQC.

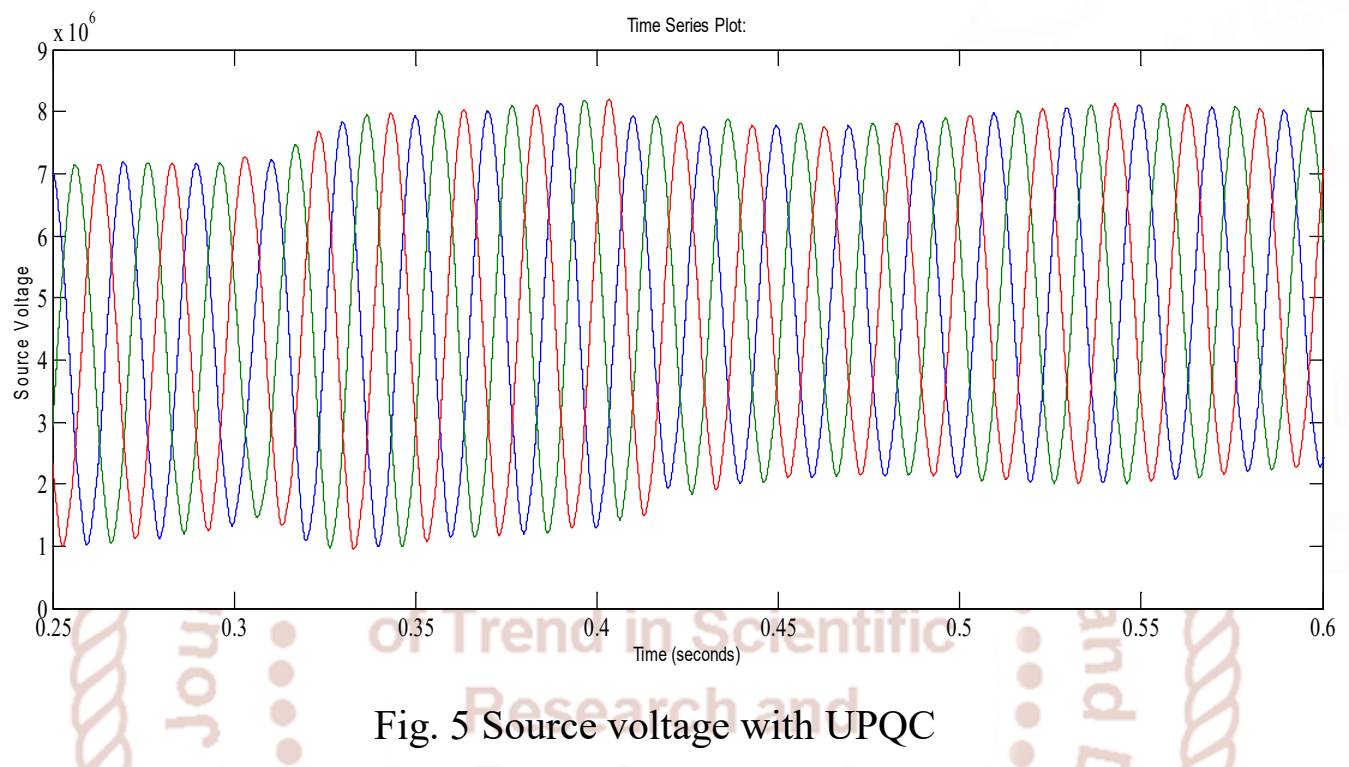

Source voltage improves from time 0.3 to $0.4 \mathrm{sec}$ as shown in Fig. 5 with UPQC. Hence UPQC mitigate the voltage the variation from 0.3 to 0.4 seconds. The voltage dip can be overcome by injecting the reactive power to the system. As the system employed with UPQC can provide reactive power support to the system, that can maintained the system voltage within prescribed limits. During the fault time the power stored in the capacitor bank of the UPQC is released to the system and hence the voltage is boosted up to the desired value.

\section{CONCLUSIONS}

In this paper, a Unified Power Quality Conditioner (UPQC) has been investigated for power quality enhancement. UPQC is an advanced hybrid filter that consists of a series active filter (APF) for compensating voltage disturbances and shunt active power filter (APF) for eliminating current distortions. Different power quality problems, their causes and consequences and the available solution have been discussed briefly. UPQC system configuration is discussed in detail. A conceptual analysis to understand the active and reactive power flow between source and load under different operating condition is carried out. The modeling of series APF, shunt APF and the UPQC has been carried out. A simple control technique, extraction of unit vector template has been used to model the control scheme for series APF. The instantaneous reactive power theory has been used to model the control scheme for shunt APF. The series and shunt are combined to configure the UPQC model.

Using hysteresis band controller the model has been developed in MATLAB/SIMULINK environment. It is found from the simulation results that UPQC improves power quality of power system by compensating harmonic and reactive current of load current which makes source current sinusoidal and it also makes load voltage sinusoidal at required voltage level by compensating with series APF.

\section{References}

1) D. M. Divan, W. E. Brumsickle, G. A. Luckjiff, J. W. Freeborg, and R. L. Hayes, "Realizing a nation-wide power quality and reliability 
monitoring system," 2003. [Online]. Available: http://www.softswitch.

com/docs/Realizing\%20a\%20Nationwide\%20Syst em\%202003.pdf

2) J. M. Guerrero, L. Garcia de Vicuna, and J. Uceda, "Uninterruptible power supply systems provide protection," IEEE Ind. Electron. Mag., vol. 1, no. 1, pp. 28-38, Spring, 2007.

3) B.Wang, G. Venkataramanan, and M. Illindala, "Operation and control of a dynamic voltage restorer using transformer coupled H-bridge converters," IEEE Trans. Power. Electron., vol. 21, no. 4, pp. 1053-1061, Jul. 2006.

4) D. M. Vilathgamuwa, H. M. Wijekoon, and S. S. Choi, "A novel technique to compensate voltage sags in multiline distribution system-The interline dynamic voltage restorer," IEEE Trans. Ind. Electron., vol. 53, no. 5, pp. 1603-1611, Oct. 2006.

5) C. N. M. Ho and H. S. H. Chung, "Fast transient control of singlephase Dynamic Voltage Restorer (DVR) without external DC source," in Proc. 37th IEEE Power Electronics Specialists Conf., Jeju, Korea, Jun. 18-22, 2006, pp. 2105-2111.

6) M. R. Banaei, S. H. Hosseini, and M. D. Khajee, "Mitigation of voltage sag using adaptive neural network with dynamic voltage restorer," in Proc. 5th Int. CES/IEEE Power Electronics and Motion Control Conf., Shanghai, China, Aug. 14-16, 2006, vol. 2, pp. 1-5.

7) A. Ghosh and G. Ledwich, "Compensation of distribution system voltage using DVR," IEEE Trans. Power Del., vol. 17, no. 4, pp 1030-1036, Oct. 2002.

8) M. K. Mishra, K. Karthikeyan, and P. K. Linash, "A development and implementation of DSP based DSTATCOM to compensate unbalanced nonlinear loads," presented at the IEEE Power India Conf., New Delhi, India, Apr. 10-12, 2006.
9) B. Singh, A. Adya, A. P. Mittal, and J. R. P. Gupta, "Analysis, simulation and control of DSTATCOM in three-phase, four-wire isolated distribution systems," presented at the IEEE Power India Conf., New Delhi, India, Apr. 10-12, 2006.

10) A. Ghosh and R. Gupta, "Frequency-domain characterization of sliding mode control of an inverter used in DSTATCOM application," IEEE Trans. Circuits Syst. I, vol. 53, no. 3, pp. 662-676, Mar. 2006.

11) G. Jianjun, X. Dianguo, L. Hankui, and G. Maozhong, "Unified power quality conditioner (UPQC): The principle, control and application," in Proc. Power Conversion Conf. (PCC), Osaka, Japan, 2002, vol. 1, pp. 80-85.

12) R. Faranda, E. Tironi, I. Valadè, and D. Zaninelli, "Power quality improvement using series electronic reactor and shunt power conditioner," in Proc. Int. Symp. and Exhib. Electric Power Engineering at the Beginning of the Third Millennium, Capri, Italy, May 12-18, 2000.

13) M. Brenna, R. Faranda, and E. Tironi, "OPEN UPQC able to improve power quality of network and loads," in Proc. Int. Congr. Electricity Distribution, Buenos Aires, Argentina, Nov. 2729, 2006. 2116 IEEE TRANSACTIONS ON POWER DELIVERY, VOL. 24, NO. 4, OCTOBER 2009

14) M. Buschmann, G. Linhofer, P.Maibach, and O. Suter, "Voltage source converter based power quality solutions," in Proc. Asia Pacific Regional Power Quality Seminar, Putrajaya, Malaysia, Mar. 28-31, 2005.

15) F. Blaabjerg, M. Newman, H. Nielsen, and J. G. Nielsen, "Control and testing of a dynamic voltage restorer (DVR) at medium voltage level," IEEE Trans. Power Electron., vol. 19, no. 3, pp. 806813, May 2004 